\title{
Body Composition in Neonates: Relationship Between Measured and Derived Anthropometry with Dual-Energy X-Ray Absorptiometry Measurements
}

\author{
WINSTON W.K. KOO, JOCELYN C. WALTERS, AND ELAINE M. HOCKMAN \\ Departments of Pediatrics and Obstetrics and Gynecology [W.W.K.K., J.C.W.], University of Tennessee, \\ Memphis, TN 38103 and Computing and Information Technology [E.M.H.], Wayne State University,
} Detroit, MI 48201

\begin{abstract}
This study examined the relationship between measured and derived anthropometric measurements with dual-energy x-ray absorptiometry measured lean and fat mass at $3.0 \pm 2.8(\mathrm{SD})$ days in 120 neonates with birth weights appropriate (AGA; $n=$ 74), large (LGA; $n=30$ ); or small (SGA, $n=16$ ) for gestational age. Anthropometric measurements, including total body weight and length, and regional measurements, including circumferences of head, chest, abdomen, midarm, and midthigh and dynamic skinfold thickness (15 and $60 \mathrm{~s}$ ) at tricep, subscapular, suprailiac, and midthigh, were performed. Derived anthropometry included muscle and fat areas, and ratios were calculated from direct measurements. The skinfold thickness measurements between 15 and 60 s were highly correlated $(r=0.973-0.996, p<$ 0.001 for all comparisons). Strong correlations existed within the four circumferences of trunk and extremities, the four skinfolds, and the ratios of weight to length and its higher powers. Weight and length accounted for $>97 \%$ of the variance of lean mass in
\end{abstract}

\section{ABSTRACT}

AGA and SGA infants and $46 \%$ of the variance in LGA infants and for 80,82 , and $84 \%$ of the variance of fat mass in SGA, AGA, and LGA infants, respectively, whereas midarm:head circumference ratio and arm muscle and fat areas are the most important derived anthropometry in the prediction for body composition. They independently accounted for up to 16.5 and $10.2 \%$, respectively, of the variance in body composition depending on the state of in utero growth. Thus, total body weight and length and some selected regional and derived anthropometry accounted for the vast majority of the variance of body composition. (Pediatr Res 56: 694-700, 2004)

Abbreviations
AGA, appropriate for gestational age
DXA, dual-energy x-ray absorptiometry
LGA, large for gestational age
SGA, small for gestational age

Weight, length, and head circumference are classic anthropometric measurements to assess growth and nutritional status in the newborn infant. Birth weight is well recognized to have prognostic value for postnatal mortality $(1,2)$, and its use in conjunction with gestation is useful for predicting morbidity (3-6). The simplicity of these measurements and the ease in training an operator to generate highly reproducible results have ensured their use in clinical situations. However, the clinical role of regional anthropometric measurement including circumference and skinfold thickness from various sites on the body and extremities is not well defined. Some reports indicated that regional anthropometry or the ratios and formulas

Received March 30, 2004; accepted June 18, 2004.

Correspondence: Winston Koo, MBBS., Hutzel Hospital, Department of Pediatrics, 4707 St. Antoine Boulevard, Detroit, MI 48201; e-mail: wkoo@wayne.edu

Supported by a University of Tennessee Medical Research Grant and by The University of Tennessee-Memphis Clinical Research Center, USPHS grant RR 00211-29.

DOI: 10.1203/01.PDR.0000142587.59238.BD derived from these measurements are good predictors of fetal growth and metabolic disturbances noted in neonates who are over- or undergrown for the duration of gestation (7-9). These refinements of regional anthropometry are thought to reflect more specific body composition, namely lean mass and fat mass $(10,11)$, which allows assessment of the quality of growth such as the extent of energy, fat and protein deposition, and the potential mechanism for disturbed metabolism in infants with abnormal in utero growth.

The aims of this study were to determine the relationship of whole-body versus regional anthropometric measurements or the calculated values on the basis of these measurements to the dual-energy x-ray absorptiometry (DXA)-measured lean mass and fat mass in neonates and to determine whether the same relationships exist regardless of deviation from normal in utero growth. We aimed to test the hypotheses that measured and derived anthropometric measurements in the neonate are highly correlated with and are predictive of DXA body com- 
position measurements and that these relationships are equally applicable regardless of normal and abnormal in utero growth.

\section{METHODS}

Subjects. Anthropometric and DXA measurements were obtained in 120 neonates at $3.0 \pm 2.8$ (SD) days after birth. Their clinical characteristics are shown in Table 1. Gestational ages of the infants as determined by maternal menstrual dating and/or ultrasound were from 30 to $42 \mathrm{wk}$ and consistent with gestational age assessment by standard examination (12). Seventy-four infants had birth weights appropriate for gestational age (AGA; 10th to 90th percentiles), 30 were large for gestational age (LGA; $>90$ percentiles), and 16 were small for gestational age (SGA; <10th percentile) according to birth weight measurements (13). The infants were part of the cohort for the study of body composition in infants with normal or abnormal in utero growth. All infants were clinically well at the time of study, and physical examination was normal without congenital malformations or dysmorphic features. This study was approved by the Institutional Review Board at the University of Tennessee, and written consent was obtained from the parent of each infant.

Anthropometric measurements. All anthropometric measurements were performed by one of the two investigators (J.C.W. or W.W.K.K.) with the help of an assistant using techniques adapted from standardized procedures (14). Body weight of each infant was determined on an electronic scale (Air Shields, Vickers, OH) to the nearest gram. Recumbent length was measured in the supine position with a length board (Ellard Instrumentation Ltd, Seattle, WA) to the nearest 0.1 $\mathrm{cm}$. Head circumference was measured at the largest occipitofrontal circumference using a paper tape measure to the nearest $0.1 \mathrm{~cm}$. Multiple readings for length and head circumference were taken for each measurement, and the final reading was taken as the average of two consecutive values within 0.2 $\mathrm{cm}$ for head circumference and $0.4 \mathrm{~cm}$ for length.

Regional anthropometry included the measurement of circumferences and skinfold thickness. Circumferences were measured using a disposable paper tape with multiple readings for each measurement, and the final reading was taken as the average of two consecutive values within $0.2 \mathrm{~cm}$. Chest (immediately below the level of the nipples) and abdomen (immediately above the umbilicus) circumferences were measured in a horizontal plane at the trunk during quiet respiration with the infant lying supine. Left limb circumferences were measured at midarm (midpoint between the acromion and olecranon) and midthigh (midpoint between the proximal border of

Table 1. Infant characteristics

\begin{tabular}{lccc}
\hline & AGA & LGA* & SGA \\
\hline$n$ & 74 & 30 & 16 \\
Birth weight (g) & $2454 \pm 634$ & $4439 \pm 337$ & $1971 \pm 522$ \\
Gestational age (wk) & $35.9 \pm 2.9$ & $39.7 \pm 0.9$ & $36.5 \pm 2.6$ \\
Gestational age $<37$ wk & 44 & 0 & 8 \\
Male/female & $43 / 31$ & $18 / 12$ & $6 / 10$ \\
White/black/Asian & $10 / 63 / 1$ & $11 / 19 / 0$ & $5 / 10 / 1$ \\
\hline
\end{tabular}

* Included nine infants of diabetic mothers. the patella and the anterior superior iliac spine) with the extremity gently extended and the infant lying on the right side and in the supine position, respectively. The distance between fixed bony prominences was measured with the extremity flexed at about 90 degrees using a flexible metal tape. All sites except those for the chest and abdomen circumference were marked with a washable marker before actual measurement.

Skinfold thickness was measured using a commercial caliper (Lange caliper; Cambridge Scientific Industries Inc., Cambridge, MD) at the following sites: tricep, subscapular, suprailiac, and midthigh on the left side. Consistency of the caliper calibration was confirmed with a manufacturer-supplied metal step phantom immediately before its use on each infant. Tricep and midthigh skinfold was measured at the same level as the midarm and midthigh circumferences. The left limb was gently extended during measurement. The infant was lying on the right side for tricep and in a supine position for midthigh measurement. Subscapular skinfold was measured at the lower angle of the scapula, in the axis of the skin crease, with the infant lying on the right side and the left arm at the side of the body. Suprailiac skinfold was measured immediately above the iliac crest, along the axis of the anterior axillary line, with the infant lying supine. The operator's left thumb and index finger were used to elevate a double fold of skin and s.c. tissue in the natural cleavage lines of the skin $\sim 1 \mathrm{~cm}$ from the site at which skinfold was to be measured. Dynamic skinfold thickness to adjust for tissue water content $(15,16)$ was determined by recording each skinfold measurement at exactly 15 and $60 \mathrm{~s}$ with a stopwatch. All measurements were to the nearest 0.1 $\mathrm{cm}$.

In our laboratory, duplicate measurements in 10 to 42 infants show similar intra- and interoperator precision as determined by the method of Gluer et al. (17). They were consistently $<1 \%$ for length and head circumference and $<3 \%$ for other circumferences. However, the precisions for the measurement of thickness of skinfolds at $15 \mathrm{~s}$ were between 8 and $14 \%$ and at $60 \mathrm{~s}$ were between 7 and $17 \%$.

DXA measurements. DXA scan acquisition was performed using a whole-body scanner (Hologic QDR 1000/W densitometer; Hologic Inc., Waltham, MA) with a two-platform system (aluminum platform overlying a foam table pad) and operated in the infant whole-body mode using the software v5.64P developed in conjunction with the manufacturer $(18,19)$. DXA scan was performed immediately preceding anthropometric measurements if the infant was asleep; otherwise, it is done immediately afterward. Both the infant and the rectangular external calibration standard (step phantom) were placed on another cotton blanket, which overlaid the platforms. Each infant was wrapped in a cotton blanket without sedation or additional restraints during the scan. Only scans without significant movement artifact (20) were analyzed for total body and regional body composition as detailed previously $(21,22)$. In our laboratory, measurements from duplicate DXA scans from 51 infants were highly significantly correlated $(r>0.99$ and $p<0.001$ for all comparisons), and the calculated (17) in vivo precision for lean mass was $1.7 \%$ and for fat mass was $5.6 \%$. 
Statistical analyses. Principal component analysis was used to determine the factorial composition among the circumference and skinfold thickness at various parts of the body and extremities to obtain a composite measurement, thus avoiding analyses of multiple colinear measurements. Pearson correlation and repeated measures and one-way ANOVAs with Bonferroni post hoc comparison were used to determine the relationships of composite circumference and skinfold measurements among AGA, LGA, and SGA infants.

The derived anthropometric measurements included ratios of weight to length, body mass index as weight/length ${ }^{2}$, and ponderal index as weight/length ${ }^{3}$. The ratios of chest, abdomen, midarm, and midthigh circumferences to head circumference were also calculated. Principal component analysis was used to determine the factorial composition among weight:length ratio, body mass index, and ponderal index. Muscle and fat area of arm and thigh were calculated according to published equations (11) with the assumption that the arm and thigh were cylindrical layers of fat overlying muscle and bone.

The contributions of measured (weight, length, four circumferences, and four skinfold thickness measured at 15 and $60 \mathrm{~s}$ ) or derived anthropometric measurements for DXA-measured total lean mass and fat mass were determined with hierarchical multiple regression. Gender, race, and gestational age were entered in all regressions as the first independent predictors of body composition.

All analyses were performed for all infants and separately for each group (AGA, LGA, and SGA) of neonates to determine whether the relationships among anthropometry and DXA measurements were affected by different in utero growth. The residuals from application of anthropometry prediction equation for body composition to each group (AGA, LGA, and SGA) were tested for difference from zero. If the anthropometric prediction equations are equivalent, i.e. able to predict DXA-measured body composition regardless of the in utero growth status, then the residuals will not be different from zero.

All statistical tests were performed with SPSS 11.5 (SPSS Inc., Chicago, IL) for Windows at an adopted significance level of 0.05. Post hoc power calculations were performed using the PASS sample size software (NCSS Inc., Kaysville, UT).

\section{RESULTS}

For each group of infants, the weight, length, circumferences, and calculated muscle and fat areas of arm and thigh and DXA measurements are shown in Table 2. Skinfold thickness measurements between 15 and $60 \mathrm{~s}$ were highly significantly correlated for all sites $(r=0.973-0.996$ and $p<0.001$ for all comparisons). Comparisons of skinfold thickness among different groups are shown in Table 3.

The strong correlations among the four circumferences produced one principal component, accounting for $96.8 \%$ of the variance, and a composite circumference was then computed for subsequent analysis. Similar computation of a composite skinfold measurement was possible because one principal component accounted for $91.2 \%$ of the variance.

Bivariate correlation of combined data from all infants indicated that the composite circumference measurements are
Table 2. Anthropometry (weight, length, circumferences, and arm and thigh muscle and fat areas) and DXA measurements

\begin{tabular}{lrcc}
\hline & AGA & LGA & SGA \\
\hline$n$ & 74 & 30 & 16 \\
Anthropometric measurements & & & \\
$\quad$ Weight $(\mathrm{g})$ & $2410 \pm 647$ & $4341 \pm 350$ & $1938 \pm 454$ \\
$\quad$ Length $(\mathrm{cm})$ & $45.1 \pm 2.7$ & $51.7 \pm 1.4$ & $43.4 \pm 2.8$ \\
Head circumference $(\mathrm{cm})$ & $32.4 \pm 2.5$ & $36.4 \pm 1.0$ & $31.0 \pm 1.6$ \\
Chest circumference $(\mathrm{cm})$ & $29.4 \pm 3.1$ & $36.8 \pm 1.3$ & $27.1 \pm 2.4$ \\
Abdomen circumference $(\mathrm{cm})$ & $28.6 \pm 2.9$ & $36.2 \pm 1.5$ & $25.9 \pm 2.3$ \\
Midarm circumference $(\mathrm{cm})$ & $8.9 \pm 1.2$ & $12.4 \pm 0.9$ & $8.1 \pm 1.1$ \\
$\quad$ Midthigh circumference $(\mathrm{cm})$ & $13.6 \pm 2.3$ & $19.3 \pm 1.4$ & $11.9 \pm 2.0$ \\
Arm muscle area $\left(\mathrm{cm}^{2}\right)$ & $5.0 \pm 1.3$ & $9.0 \pm 1.3$ & $4.2 \pm 1.1$ \\
$\quad$ Arm fat area $\left(\mathrm{cm}^{2}\right)$ & $1.4 \pm 0.5$ & $3.1 \pm 1.0$ & $1.0 \pm 0.3$ \\
Thigh muscle area $\left(\mathrm{cm}^{2}\right)$ & $12.6 \pm 4.1$ & $22.6 \pm 3.1$ & $9.8 \pm 3.2$ \\
$\quad$ Thigh fat area $\left(\mathrm{cm}^{2}\right)$ & $2.2 \pm 1.1$ & $6.4 \pm 2.3$ & $1.6 \pm 0.6$ \\
DXA measurements of total body & & & \\
$\quad$ Lean mass $(\mathrm{g})$ & $2131 \pm 504$ & $3386 \pm 194$ & $1775 \pm 387$ \\
Fat mass $(\mathrm{g})$ & $312 \pm 167$ & $1029 \pm 324$ & $204 \pm 98$ \\
Fat mass $(\%)$ & $11.9 \pm 3.5$ & $22.5 \pm 5.6$ & $10.0 \pm 2.7$ \\
\hline
\end{tabular}

Table 3. Skinfold thickness measurements at 15 and $60 \mathrm{~s}$

\begin{tabular}{lccc}
\hline & AGA & LGA & SGA \\
\hline$n$ & 74 & 30 & 16 \\
Tricep skinfold & & & \\
$\quad 15 \mathrm{~s}$ & $3.6 \pm 0.9$ & $5.8 \pm 1.6^{*}$ & $2.9 \pm 0.5$ \\
$60 \mathrm{~s}$ & $3.2 \pm 0.8$ & $5.3 \pm 1.5^{*}$ & $2.6 \pm 0.5$ \\
$\quad$ Difference (mm) & $0.39 \pm 0.12$ & $0.53 \pm 0.17^{*}$ & $0.33 \pm 0.11$ \\
$\quad$ Difference (\%) & $11.2 \pm 3.4$ & $9.2 \pm 2 .{ }^{\dagger}$ & $11.4 \pm 3.8$ \\
Subscapular skinfold & & & \\
$15 \mathrm{~s}$ & $3.4 \pm 0.8$ & $5.9 \pm 1.7^{*}$ & $2.7 \pm 0.6$ \\
$60 \mathrm{~s}$ & $3.1 \pm 0.8$ & $5.4 \pm 1.7^{*}$ & $2.4 \pm 0.6$ \\
Difference (mm) & $0.36 \pm 0.11$ & $0.49 \pm 0.16^{*}$ & $0.36 \pm 0.11$ \\
Difference (\%) & $10.9 \pm 3.3$ & $8.8 \pm 3.1^{*}$ & $13.6 \pm 4.5 \dagger, \S$ \\
Suprailiac skinfold & & & \\
$15 \mathrm{~s}$ & $3.2 \pm 0.8$ & $5.9 \pm 1.8^{*}$ & $2.5 \pm 0.7$ \\
$60 \mathrm{~s}$ & $2.8 \pm 0.8$ & $5.3 \pm 1.8^{*}$ & $2.2 \pm 0.7$ \\
$\quad$ Difference (mm) & $0.35 \pm 0.11$ & $0.59 \pm 0.17^{*}$ & $0.33 \pm 0.09$ \\
$\quad$ Difference (\%) & $11.4 \pm 3.8$ & $10.6 \pm 3 .{ }^{*}$ & $13.5 \pm 3.6$ \\
Midthigh skinfold & & & \\
$15 \mathrm{~s}$ & $3.7 \pm 1.2$ & $7.7 \pm 2.3^{*}$ & $3.0 \pm 0.8$ \\
$\quad 60 \mathrm{~s}$ & $3.3 \pm 1.1$ & $7.0 \pm 2.3^{*}$ & $2.6 \pm 0.7$ \\
Difference (mm) & $0.41 \pm 0.18$ & $0.76 \pm 0.21^{*}$ & $0.38 \pm 0.14$ \\
$\quad$ Difference (\%) & $11.3 \pm 3.8$ & $10.4 \pm 3.4$ & $12.7 \pm 3.9$ \\
\hline
\end{tabular}

$*$ Differs from AGA and SGA groups, $p<0.01$ all comparisons.

$\dagger$ Differs from AGA, $p<0.05$.

$\$$ Differs from SGA, $p<0.05$.

$\S$ Differs from LGA, $p<0.05$.

significantly correlated with lean and fat mass $(r=0.97$ and 0.92 , respectively, $p<0.01$ for all comparison) and similar findings with the composite skinfold measurements $(r=0.91$ for fat mass, $p<0.01 ; r=0.75$ for lean mass, $p<0.01$ ). When applied to individual groups, the correlations between the composite circumference and skinfold measurement with lean and fat mass were similar for the AGA and SGA groups. For the LGA group, these composite measurements significantly correlated with fat mass but not with lean mass. The correlations with fat mass as percentage of body weight is slightly but consistently lower than that for absolute fat mass.

Principal component analysis of the ratios of weight to length and its higher powers indicated that a single composite score could account for $>92 \%$ of the total variance. Weight/ 
length ${ }^{2}$ alone could account for $>99 \%$ of this variance regardless of AGA, LGA, and SGA groups, and it was used as the only ratio between weight and length for subsequent analysis.

The predictability of measured or derived anthropometry for DXA-measured total body lean and fat mass are shown in Tables $4-6$. The predictability for body composition generally shows slightly higher variance when applied to all infants rather than to each of the groups (AGA, LGA, or SGA) because of greater heterogeneity from combining all groups, i.e. no restriction of variance. The prediction for lean mass is consistently better than that for fat mass, which in turn was better than that for fat percentage for AGA and SGA infants (data not shown) in comparison to LGA infants.

Weight and length were consistently the best predictors of body composition, as was body mass index, even when race, gender, and gestation were included in the regression (Tables 4-6). In the presence of weight and length, the measured circumferences (chest, abdomen, midarm, and midthigh) contributed an additional $5.1 \%$ of the variance in the prediction of lean mass in LGA group and $1.8-3.4 \%$ of the variance of fat mass in the three groups (Table 4). Skinfold measurement contributed an additional $22.5 \%$ of the variance in the prediction of lean mass in LGA group and $6.3-8.4 \%$ of the variance in the prediction of fat mass in the three groups (Table 4).

Of the ratios calculated from measured anthropometry, the ratio weight:length ${ }^{2}$ was the dominant predictor of body composition in all groups except for lean mass in the LGA group. Weight:length ${ }^{2}$ alone accounted for $>81 \%$ of the variance in the prediction of lean mass in the AGA and SGA groups and $67-74 \%$ of the variance in the prediction of fat mass (Table 5).

In the presence of weight and length, the addition of derived arm and thigh muscle and fat area using reported formulas (11) accounted for $10.5 \%$ of the variance in the prediction of lean mass in LGA group only and $2.9-9.1 \%$ of the variance in the prediction of fat mass in the three groups (Table 6). The addition of thigh muscle and fat areas to arm muscle and fat areas resulted in minimal or no improvement in the prediction of body composition.

For all prediction equations of body composition generated from the use of either the measured or derived anthropometry, the lowest variance in lean mass was noted in LGA infants and the lowest variance in fat mass was noted in SGA infants. Furthermore, the prediction equations generated from mea- sured or calculated anthropometry of all infants were less accurate for the prediction of lean or fat mass in the SGA group than other groups, and the prediction equations based on calculated anthropometry ratios of all infants were less accurate for the prediction of fat mass in the AGA group than other groups. Except for the $R^{2}$ values $<0.24$, the power associated with all $R^{2}$ reported is at a minimum of 0.96 (Tables $4-6$ ).

\section{DISCUSSION}

In the neonate, the classic anthropometry of weight and length are well known to have significant correlation with and be predictive of multiple components of body composition (22-26), thereby allowing assessment of the quality of growth such as the extent of energy, fat, and protein deposition. Further refinement of anthropometry calibrated against a validated measure of body composition potentially could better define the role of whole-body or regional anthropometry as a means for objective quantification of lean and fat mass. However, the relative importance of whole-body or regional measurements or values derived from these measurements is not well defined.

This report represents a comprehensive study of neonates on the relative contribution of multiple measured and derived anthropometry for the prediction of body composition, specifically DXA-measured lean and fat mass. The goal of this study was to determine relative value of different aspects of anthropometry in the prediction of body composition. It is not meant to determine the effect of variations (normal or abnormal) in in utero growth on changes in anthropometry or DXA measurements. Thus, the heterogeneity of our infant population with a large range of gestational ages and amounts of lean and fat mass would enhance rather than detract from the understanding of the value of various measured and derived anthropometry in the prediction of body composition.

Body composition was determined using a reference method, DXA, because its use in small infants was validated independently by multiple investigators $(18,19,27,28)$. We have also shown that the measurement from pencil-beam DXA technique used in this study is highly predictive of those obtained by the newer fan-beam DXA technique (29). Thus, our conclusions would be valid regardless of the DXA technique used. Another strength of this study is that all measure-

Table 4. $\mathrm{R}^{2}$ in the prediction of body composition from hierarchical addition of independent variables: clinical parameters and anthropometry measurements including the composite scores from the principal component analysis of multiple body and limb circumferences and thickness of multiple skinfolds

\begin{tabular}{|c|c|c|c|c|c|}
\hline & $\begin{array}{l}\text { Gender, race, } \\
\text { gestation }\end{array}$ & $\begin{array}{l}\text { Plus weight } \\
\text { and length }\end{array}$ & $\begin{array}{l}\text { Plus standardized } \\
\text { circumference }\end{array}$ & $\begin{array}{l}\text { Plus standardized } \\
\text { skinfold }\end{array}$ & $\begin{array}{l}\text { Weight and } \\
\text { length only }\end{array}$ \\
\hline \multicolumn{6}{|l|}{ Lean mass } \\
\hline All groups & 0.744 & 0.974 & 0.974 & 0.981 & 0.968 \\
\hline LGA & 0.065 & 0.510 & 0.513 & 0.687 & 0.462 \\
\hline SGA & 0.937 & 0.992 & 0.992 & 0.992 & 0.991 \\
\hline \multicolumn{6}{|l|}{ Fat mass } \\
\hline LGA & 0.237 & 0.859 & 0.860 & 0.905 & 0.842 \\
\hline SGA & 0.787 & 0.835 & 0.836 & 0.886 & 0.802 \\
\hline
\end{tabular}


Table 5. $\mathrm{R}^{2}$ in the prediction of body composition from hierarchical addition of independent variables: clinical parameters and ratios of anthropometry measurements (weight to length ${ }^{2}$; chest, abdomen, midarm, and midthigh circumference to head circumference)

\begin{tabular}{|c|c|c|c|c|c|c|c|}
\hline & $\begin{array}{c}\text { Gender, race, } \\
\text { gestation }\end{array}$ & $\begin{array}{l}\text { Plus weight/ } \\
\text { length }^{2}\end{array}$ & Plus CC:HC & Plus AC:HC & Plus MA:HC & Plus MT:HC & $\begin{array}{c}\text { Weight/ } \\
\text { length }{ }^{2} \text { only }\end{array}$ \\
\hline \multicolumn{8}{|l|}{ Lean mass } \\
\hline All groups & 0.744 & 0.912 & 0.912 & 0.912 & 0.914 & 0.914 & 0.877 \\
\hline LGA & 0.065 & 0.066 & 0.114 & 0.134 & 0.165 & 0.174 & 0.000 \\
\hline SGA & 0.937 & 0.967 & 0.967 & 0.968 & 0.976 & 0.980 & 0.848 \\
\hline \multicolumn{8}{|l|}{ Fat mass } \\
\hline LGA & 0.237 & 0.747 & 0.761 & 0.769 & 0.797 & 0.819 & 0.726 \\
\hline SGA & 0.787 & 0.806 & 0.811 & 0.811 & 0.818 & 0.877 & 0.668 \\
\hline
\end{tabular}

CC, AC, MAC, MTC, HC, circumference of chest, abdomen, midarm, midthigh, and head, respectively.

Table 6. $\mathrm{R}^{2}$ in the prediction of body composition from hierarchical addition of independent variables: clinical parameters and derived anthropometry measurements (arm and thigh muscle area)

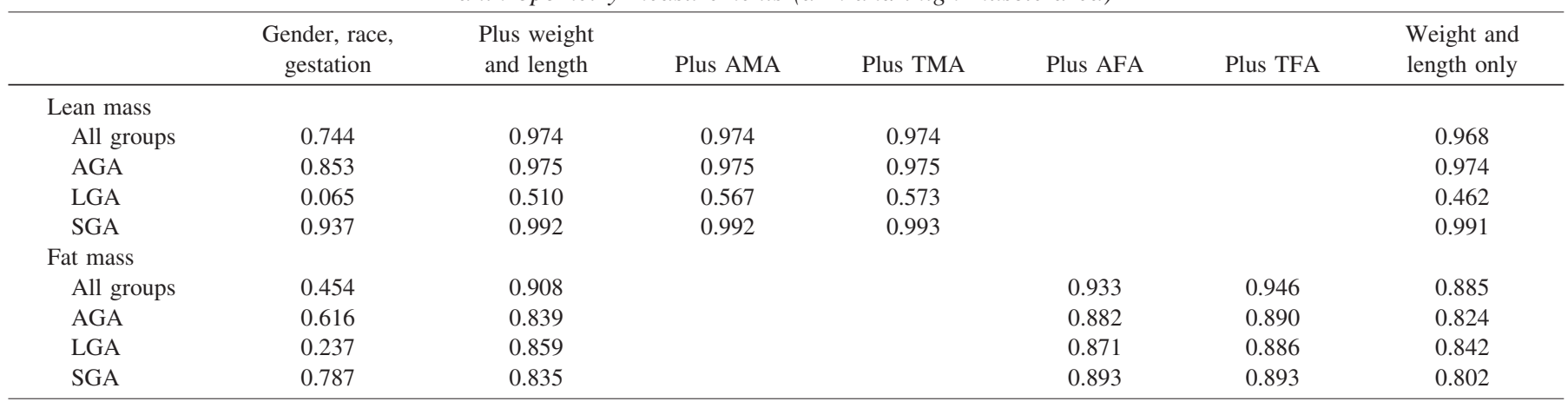

AMA and TMA, arm and thigh muscle area, respectively; AFA and TFA, arm and thigh fat area, respectively.

ments were performed by two experienced investigators (J.C.W. and W.W.K.K.) with interoperator precision well within the published range $(14,15,30,31)$. Our data demonstrated that directly measured anthropometry has excellent predictive value for body composition in a heterogeneous population of neonates. In our analysis, we controlled for race and gender, which could have a small but independent effect on body composition $(21,22,24,26,32)$, and also controlled for gestational age to adjust for the over- or undergrown neonate for the same gestation. Anthropometry, in conjunction with race, gender, and gestation, accounted for as much as $98 \%$ of the variance for lean mass and almost $94 \%$ of the variance for fat mass. Weight and length alone accounted for the majority of this predictive ability and accounted for $>96 \%$ and $>88 \%$ of the variance for lean and fat mass, respectively.

Our data demonstrated that measured regional anthropometry, specifically, the circumference and skinfold measurements at various sites of the trunk and extremities, have strong correlation with lean and fat mass. This is consistent with high correlation between circumferences and fat-free or fat mass reported by other investigators (33). However, our data show that the relative explanatory value of regional anthropometry for body composition is much less than the classic whole-body anthropometry.

The circumferences have minimal contribution to the prediction of body composition when compared with weight and length. In contrast, skinfold thickness has an independent predictive value for fat and lean mass. The lower correlation and predictive value of all anthropometric measurements for fat mass as a percentage of body weight versus the absolute fat mass is consistent with isotope-labeled water studies (34), another reference method for the measurement of body fat. In this study, skinfold thickness accounted for $\sim 20 \%$ of the variance of lean mass in LGA neonates. This is consistent with the increase in fat mass in LGA infants, which presumably is a surrogate for the increased lean mass (35). This is also consistent with the report that skinfold thickness is correlated with fat-free mass (33).

Dynamic skinfold measurement has the theoretical advantage of minimizing the effect of s.c. water on skinfold thickness $(15,16)$. However, our data demonstrated the extremely high linear relationship between the 15- and 60-s skinfold measurements at all sites. Our findings when coupled with the report that the slope of decrease in skinfold thickness starts to plateau within a few seconds after the application of the caliper (15) support the adequacy of a 15-s skinfold thickness measurement for the purpose of body composition estimation.

The use of ratios of weight to length to determine the appropriateness of growth $(23,33)$ and the use of midarm circumference to head circumference ratio and ponderal index (7-9) in the prediction of symptomatic metabolic abnormalities in neonates with abnormal in utero growth are reflections of the differential growth and body composition in situations of under- or overnutrition, with length and head circumference usually affected to a relatively lesser extent than weight and circumferences at the trunk or extremities. These indicators of differential response to varied nutrition state theoretically increase the discriminatory power to detect disturbances in 
growth and body composition and therefore metabolic disturbance. These assumptions are consistent with our data that the ratios of body and limb circumferences to head circumference have a greater independent predictive value on body composition of infants with abnormal in utero growth.

Our data indicated that body mass index (weight/length ${ }^{2}$ ) is consistently the best ratio for the predictability of body composition except for lean mass in LGA infants. The lack of predictability of body mass index or the ratios from regional anthropometry for lean mass in the LGA group was presumably the result of homogeneity of the body weights in this group. Furthermore, in LGA neonates, both weight and length have varied independent and interactive predictive effect on body composition, and they have disproportionate increase in fat mass (35). The latter in turn could have disproportionately increased body and limb circumferences and negatively affected the relationship with lean mass.

The derived anthropometric values using equations based on the assumption that various regions of the body and extremities are cylinders $(10,11)$ have some theoretical advantages compared with the use of simple ratios. However, this assumption is likely an oversimplification of the anatomy and is consistent with the reports of their poor agreement with body composition measured by reference laboratory methods including total body electrical conductivity (36) or DXA (37) in infants. This is also consistent with our finding that the addition of calculated arm and thigh muscle or fat areas contributed little to the variance in the prediction of lean and fat mass compared with the use of weight and length alone. In our study, the combination of thigh and arm muscle and fat area was no better than the use of arm muscle or fat area alone for the prediction of body composition.

Traditionally, the use of multiple sites for the determination of circumference and skinfold in the assessment of body composition is to minimize the measurement error. However, as our data showed extremely high correlation of circumference and skinfold thickness among different sites, it seems reasonable to recommend that anthropometric measurements at a single region in addition to total body weight and length could account for body composition with similar effectiveness as the use of multiple additional regional and derived anthropometric values. Our data indicated that tricep site is the most relevant single region because midarm circumference and tricep skinfold could provide a ratio against head circumference and calculated arm muscle and fat areas that maximized the predictive value of anthropometry for body composition.

\section{CONCLUSION}

We conclude that measured and derived anthropometry from weight and length, head circumference, midarm circumference, and triceps skinfold measurements offers the maximum predictive value for body composition in neonates. Midarm circumference:head circumference ratio and arm muscle and fat areas are the most important derived anthropometry in the prediction for body composition. A 15 -s skinfold thickness is as effective as the 60-s measure- ment. The predictability of anthropometry for body composition may be altered in infants with abnormal in utero growth.

\section{REFERENCES}

1. Williams RL, Creasy RK, Cunningham GC, Hawes WE, Norris FD, Tashiro M 1982 Fetal growth and perinatal viability in California. Obstet Gynecol 59:624632

2. Lemons JA, Bauer CR, Oh W, Korones SB, Papile LA, Stoll BJ, Verter J, Temprosa M, Wright LL, Ehrenkranz RA, Fanaroff AA, Stark A, Carlo W, Tyson JE, Donovan EF, Shankaran S, Stevenson DK 2000 Very low birth weight outcomes of the National Institutes of Child Health and Human Development Neonatal Research Network, January 1995 through December 1996. Pediatrics 107:E1

3. Battaglia FC, Lubchenco LO 1967 A practical classification of newborn infants by weight and gestational age. J Pediatr 71:159-163

4. Lubchenco LO, Bard H 1971 Incidence of hypoglycemia in newborn infants classified by birth weight and gestational age. Pediatrics 47:831-838

5. Modanlou HD, Dorchester WL, Thorosian A, Freeman RK 1980 Macrosomiamaternal, fetal, and neonatal implications. Obstet Gynecol 55:420-424

6. Kramer MS, Olivier M, McLean FH, Willis DM, Usher RH 1990 Impact of intrauterine growth retardation and body proportionality on fetal and neonatal outcome. Pediatrics 85:707-713

7. Georgieff MK, Sasanow SR, Mammel MC, Pereira GR 1986 Mid-arm circumference/ head circumference ratios for identification of symptomatic LGA, AGA, and SGA newborn infants. J Pediatr 109:316-321

8. Georgieff MK, Sasanow SR, Chockalingam UM, Pereira GR 1988 A comparison of the mid-arm circumference/head circumference ratio and ponderal index for the evaluation of newborn infants after abnormal intrauterine growth. Acta Paediatr Scand 77:214-219

9. Drossou V, Diamanti E, Noutsia H, Konstantinidis T, Katsougiannopoulos V 1995 Accuracy of anthropometric measurements in predicting symptomatic SGA and LGA neonates. Acta Pediatr 84:1-5

10. Dauncey MJ, Gandy G, Gairdner D 1977 Assessment of total body fat in infancy from skinfold thickness measurements. Arch Dis Child 52:223-227

11. Sann L, Durand M, Picard J, Lasne Y, Bethenod M 1988 Arm fat and muscle area in infancy. Arch Dis Child 63:256-260

12. Ballard JL, Khoury JC, Wedig K, Wang L, Eilers-Walsman BL, Lipp R 1991 New Ballard score, expanded to include extremely premature infants. J Pediatr 119:417-423

13. Brenner WE, Edelman DA, Hendricks CH 1976 A standard of fetal growth for the United States of America. Am J Obstet Gynecol 126:555-564

14. Lohman TG, Roche AF, Martorell R (eds) 1988 Anthropometric Standardization Reference Manual. Human Kinetics Books, Champaign, pp 1-80

15. McGowan A, Jordan M, MacGregor J 1974 Skinfold thickness in neonates. Biol Neonate 25:66-84

16. Thornton CJ, Shannon DL, Hunter MA, Brans YW 1982 Dynamic skinfold thickness measurements: a noninvasive estimate of neonatal extracellular water content. Pediatr Res 16:989-994

17. Gluer CC, Blake G, Lu Y, Blunt BA, Jergas M, Genant HK 1995 Accurate assessment of precision errors: how to measure the reproducibility of bone densitometry techniques. Osteoporos Int 5:262-270

18. Koo WW, Massom LR, Walters J 1995 Validation of accuracy and precision of dual energy x-ray absorptiometry for infants. J Bone Miner Res 10:1111-1115

19. Koo WW, Hockman EM, Hammami M 2004 Validation of bone mass and body composition measurements in small subjects with pencil beam dual energy X-ray absorptiometry. J Am Coll Nutr 23:79-84

20. Koo WW, Walters J, Bush AJ 1995 Technical considerations of dual energy x-ray absorptiometry-based bone mineral measurements for pediatric studies. J Bone Miner Res 10:1998-2004

21. Koo WW, Bush AJ, Walters J, Carlson SE 1998 Postnatal development of bone mineral status during infancy. J Am Coll Nutr 17:65-70

22. Koo WW, Walters JC, Hockman EM 2000 Body composition in human infants at birth and postnatally. J Nutr 130:2188-2194

23. Catalano PM, Tyzbir ED, Allen SR, McBean JH, McAuliffe TL 1992 Evaluation of fetal growth by estimation of neonatal body composition. Obstet Gynecol 79:46-50

24. Catalano PM, Drago NM, Amini SB 1995 Factors affecting fetal growth and body composition. Am J Obstet Gynecol 172:1459-1463

25. Catalano PM, Thomas AJ, Avallone DA, Amini SB 1995 Anthropometric estimation of neonatal body composition. Am J Obstet Gynecol 173:1176-1181

26. Rigo J, Nyamugabo K, Picaud JC, Gerard P, Pieltain C, De Curtis M 1998 Reference values of body composition obtained by dual energy X-ray absorptiometry in preterm and term neonates. J Pediatr Gastroenterol Nutr 27:184-190

27. Picaud JC, Rigo J, Nyamugabo K, Milet J, Senterre J 1996 Evaluation of dual energy $\mathrm{x}$-ray absorptiometry for body composition assessment in piglets and term human neonates. Am J Clin Nutr 63:157-163

28. Fusch C, Slotboom J, Fuehrer U, Schumacher R, Keisker A, Zimmermann W, Moessinger A, Boesch C, Blum J 1999 Neonatal body-composition: dual-energy $\mathrm{X}$-ray absorptiometry, magnetic resonance imaging, and three-dimensional chemical shift imaging versus chemical analysis in piglets. Pediatr Res 46:465-473

29. Koo WW, Hammami M, Hockman EM 2003 Interchangeability of pencil-beam and fan-beam dual energy X-ray absorptiometry measurements in piglets and infants. Am J Clin Nutr 78:236-240

30. Branson RS, Vaucher YE, Harrison GG, Vargas M, Thies C 1982 Inter- and 
intra-observer reliability of skinfold thickness measurements in newborn infants. Hum Biol 54:137-143

31. Ellis KJ 2001 Selected body composition methods can be used in field studies. J Nutr 131:1589S-1595S

32. Koo B, Walters J, Hockman E, Koo W 2002 Body composition of newborn twins: Intrapair differences. J Am Coll Nutr 21:245-249

33. Butte NF, Wong WW, Fiorotto M, Smith EO, Garza C 1995 Influence of early feeding mode on body composition of infants. Biol Neonate 67:414-424

34. Sheng HP, Muthappa PB, Wong WW, Schanler RJ 1993 Pitfalls of body fat assessments in premature infants by anthropometry. Biol Neonate 64:279-286
35. Hammami M, Walters JC, Hockman EM, Koo WW 2001 Disproportionate alterations in body composition of large for gestational age neonates. J Pediat 138:817-821

36. de Bruin NC, van Velthoven KA, Stijnen T, Juttmann RE, Degenhart HJ, Visser HK 1995 Body fat and fat-free mass in infants: new and classic anthropometric indexes and prediction equations compared with total-body electrical conductivity. Am J Clin Nutr 61:1195-1205

37. Schmelzle HR, Fusch C 2002 Body fat in neonates and young infants: validation of skinfold thickness versus dual energy X-ray absorptiometry. Am J Clin Nutr 76:1096-1100 